\section{HABITAR A TERRA E A GENTE DO LUGAR - UMA ABORDAGEM FENOMENOLÓGICA PARA \\ COMPREENSÃO DA MEMÓRIA DE \\ SERINGUEIRIROS DO ESTADO DO ACRE}

Janaina Mourão Freire'

\section{INTRODUÇÃO}

[...] às vezes eu me deito, eu fecho os olhos e eu vejo a minha estrada todinha assim... aquelas seringa por onde andava, [...] parece que eu tô vendo aquilo tudo

a gente vê no pensamento da gente.

Aldenir José Cardoso, soldado da borracha, 79 anos

A filosofia cartesiana que se desenvolveue foi a grande representante da modernidade tinha duas características principais: o pragmatismo e o antropocentrismo. Desta forma, o homem era posicionado isolado da natureza e, muitas vezes, superior a ela. As análises deviam se centrar no tangivel e qualquer dogma, crença, fé, enquanto metafísico, era não científico. A Revolução Industrial alimentou essas ideias e a técnica se transformou no elemento fundamental para a sociedade. As ciências se subdividiram naquelas consideradas como da natureza e as que se dedicam ao homem - as ciências sociais:

Mestranda pelo Programa de Pós-Graduação em Geografia, Instituto de Estudos Sócio-Ambientais (IESA), Universidade Federal de Goiás (UFG). janainamourao@gmail.com.

$\checkmark \mathrm{SHIN}, \mathrm{Ol}$ 10, Conjunto 11, casa 01, Lago Norte. Brasília, DF. 71525-110.

Geograficidade | v.3, n.1, Verão 2013

ISSN 2238-0205
Qualquer tentativa de pensar o homem e a natureza de uma forma orgânica e integrada torna-se agora mais difícil, até porque a divisão não se dá somente enquanto pensamento. A realidade objetiva construída pelos homens - o que inclui, obviamente, a subjetividade, sem o que o homem se transforma num ser exclusivamente biológico - está toda dividida [...].(PORTOGONÇALVES, 2001, p. 35)

A relação homem-meio analisada de maneira integrada deve considerar não apenas os aspectos físicos e biológicos de um e de outro, mas também a relação imaterial existente entre ambos. Negá-la tem sido frequente nos estudos geográficos. No entanto, com a entrada do paradigma fenomenológico na Geografia, esta tem se dedicado à memória e ao imaginário do homem, preocupando-se em conhecer aquilo que reside no ambiente simbólico e intangível (ALMEIDA, 2008).

Anne Buttimer reflete sobre a recusa da ciência em investigar fatos que têm sido delegados aos místicos, poetas e filósofos:

Estranha, na verdade, soa a linguagem de poetas e filósofos; ainda mais estranha é a recusa da Ciência em ler e ouvir sua mensagem. O geógrafo humanístico, afinado com as vozes do cientista e do filósofo, não pode dar-se ao luxo de ignorar qualquer coisa que possa lançar luz nas complexidades do relacionamento do homem com a terra. (BUTTIMER, 1982, p. 166)

No relacionamento do homem com a terra formam-se lugares. Ao habitaraTerra, construímos um lar-um lugare estabelecemos relações afetivas pelas vivências. Mas para compreender o nosso processo de habitar e de constituição de lugares é necessário que partamos de uma base filosófica que permita o alcance disso e acreditamos que a Fenomenologia, grande influenciadora da Geografia Cultura Humanista, seja o caminho ideal a se percorrer. As trilhas são diversas e por isso a necessidade de primeiramente compreendermos o que 
é fenomenologia para, em seguida, refletir sobre como habitamos e como significamos lugares.

O interesse por esse tema deve-se à pesquisa de mestrado que vem sendo realizada no programa de pós-graduação em Geografia da Universidade Federal de Goiás, sob a orientação da professora Maria Geralda de Almeida. O objetivo é compreender como se constitui a memória de seringueiros que foram Soldados da Borracha no estado do Acre. Para analisar e compreender as lembranças captadas por entrevistas durante as pesquisas de campo tornou-se fundamental que antes enxergássemos os seringueiros como indivíduos que habitaram os seringais - locais com dinâmica muito singular - e que ali estabeleceram relações afetivas que vão além das dificuldades materiais enfrentadas ao longo dos anos de vida na floresta. Por essa ponte epistemológica e teórica, percebeu-se que os seringais da Amazônia constituem um lugar que faz parte de um passado ainda presente, visto que esses homens são aposentados sob o mesmo título que receberam quando enviados às colocações de seringa para atender à demanda por borracha na Segunda Guerra Mundial: Soldados da Borracha.

\section{ABORdAGENS FENOMENOLÓgICAS - DA AlemANHA PARA O MUNDO}

Como compreender a fenomenologia? Vamos ao menos tentar, pois como nos diz Anne Buttimer (1982, p. 168): "Não é fácil definir a fenomenologia". O termo pode ser encontrado em Edmund Husserl, Kant, Merleau-Ponty, Martin Heidegger, Jean-Paul Sartre e outros.

Edmund Husserl era um matemático alemão "muito sensível à influência da psicologia" (ALES BELLO, 2004, p. 60). A partir de raciocínios sobre as operações matemáticas criou o que ele chamou de Fenomenologia. Era contundente quando falava das limitações do positivismo, embora nunca tenha deixado de registrar a importância de um método. Por não ter tido uma iniciação filosófica durante sua formação acadêmica, conheceu pouco da filosofia medieval, mas dialogou com muitos estudiosos da modernidade. Issolhe era vantajoso porque buscava a verdade sem a influência de tradições filosóficas, mas era também desvantajoso pela necessidade de construir um caminho de forma autodidata. O pesquisador alemão morou e trabalhou em duas pequenas cidades: Gottingen e Friburgo e teve discípulos que o acompanhava. Entre os discípulos, alguns eram mulheres, o que era raro na primeira década do século XX. Costumavam ter uma relação de amizade e distribuíam-se em temáticas distintas para o uso do método fenomenológico, sendo muitos desses trabalhos publicados na revista "Anuário da Fenomenologia" criada por Edmund Husserl. Angela Bello (2004, p. 64) afirma: "Com efeito, podemos dizer que a fenomenologia não é apenas uma corrente filosófica, mas uma escola filosófica, pois entre o mestre e os discípulos havia relacionamentos de amizade cotidianos".

As suas ideias eram escritas com a técnica da estenografia, ele mesmo criara uma para si e seus assistentes deviam aprendê-la para decodificação dos textos. Com o uso de sinais breves ele conseguia ser extremamente rápido na escrita. Alguns de seus escritos, que hoje estão conservados no Arquivo de Louvain, na Bélgica, ainda não foram transcritos.

Edmund Husserl buscava a consciência da essência pura a partir da transcendência a possíveis pré-julgamentos que existam. O objetivo era romper com postulados a priori que as ciências possuem. Para tanto, ele propunha que o homem voltasse para dentro de si, reconhecendo-se como um sujeito intencional. "[...] a fenomenologia poderia ser definida como um modo filosófico de reflexão a respeito da experiência consciente" (BUTTIMER, 1982, p. 170) que pode ser 
alcançada por meio do princípio de redução de Husserl, como veremos mais adiante.

Werther Holzer explica que a intencionalidade é a situação original, o fato primitivo. Isso significa que os fenômenos são percebidos, mas percebidos antes de tudo por uma intenção e é só através dessa intencionalidade que se torna possível a redução fenomenológica (ou redução transcendental). Edmund Husserl se influencia por Brentano, um filósofo da escolástica que usou esse termo pela primeira vez, mas o modifica para inseri-lo na fenomenologia. O filósofo alemão criticava a razão cartesiana que considerava como objetivo apenas os estudos voltados a objetos quantificáveis, pois acreditava que a razão se refere à essência humana mesmo que esta não seja enumerável. Edmund Husserl percebia a ruptura entre o mundo da ciência e o mundo da vida e considerava que isso devia ser revertido. Para tanto, construiu duas reduções: a redução eidética e a redução transcendental (HOLZER, 2010).

Edmundo Husserl utiliza o termo "reduzir" no sentido de diminuir a partir da retirada de algo. A redução eidética é reduzir à essência. Para tanto, o matemático alemão utiliza-se de parênteses. Algo que é colocado em parênteses não deixa de existir, apenas não é relevante para um dado momento. No caso da redução eidética, coloca-se entre parênteses a existência, ou seja, "nós tiramos a existência fatual, sendo que permanece a essência" (ALES BELLO, 2004, p. 85). A existência é o óbvio, a essência é o que deve ser posto em evidência. A redução transcendental também é denominada de redução ao sujeito (Werther Holzer e Nicholas Entrikin denominam de redução fenomenológica). Ela coloca entre parênteses o indivíduo para chegar ao verdadeiro eu do sujeito (sujeito entendido como ser humano). Esse verdadeiro eu é a percepção. Edmund Husserl exemplifica isso ao falar da folha de papel, pois o papel existe, mas a existência do papel não importa, mas sim ele enquanto cogitatio, ou seja, enquanto vivido de consciência e consciência no sentido de "dar-se conta", ou seja, perceber. É o percebido que deve ser colocado em evidência:

Diante de mim, na penumbra, está esse papel branco. Eu o vejo, toco. Esse ver e tocar [...] para mim é um cogitatio, um vivido de consciência. Esse papel, mesmo com suas propriedades objetivas, com sua extensão no espaço, situado objetivamente em relação à coisa espacial que chamo meu corpo, não é cogitatio, mas cogitatum, não vivido de percepção, mas percebido (HUSSERL, 2006, p. 86-87).

O matemático alemão se utiliza do termo Erlebnis que significa "estou vivendo exatamente isso nesse momento", podendo ser traduzido no português por "vivência" para explicar esse perceber. Enquanto percebido é vivência e não vivido, porque não é passado, é o momento. A folha de papel exemplificada está dentro de nós enquanto percepção, mas não enquanto conteúdo concreto. Ela está imanente no sujeito e transcendente por existir fora de nós e a Fenomenologia não se interessa pela existência, mas sim pela essência. Portanto, nessa etapa a redução transcendental dedica-se ao percebido. Se nós vemos a folha de papel diante de todo um contexto que está ao nosso redor e damos atenção justamente à folha é porque existe uma intencionalidade na nossa percepção (HUSSERL, 2006).

Edmund Husserl acredita que para se conhecer um fenômeno cultural, é necessário ir fundo, escavar, realizar um trabalho de arqueólogo: "Para Husserl, ir até o fundo dos fenômenos culturais [...] significa ir a fundo no estudo dessas estruturas das vivências, ou seja, ver como elas são organizadas e como elas se manifestam" (ALES BELLO, 2004, p. 100).

Edmund Husserl (2006) traz ainda o conceito de "ato". Os atos são as vivências (Erlebnis). Temos o ato de perceber, o ato de recordar, 
o ato de imaginar ou fantasiar e outros. Esses atos/vivências estão relacionados a três grupos que são interligados: o corporal, o psíquico e o espiritual (moral). Esses grupos da vivência devem nortear uma análise fenomenológica de modo que se possa compreender a própria vivência, ou seja, o ato em si. Na presente pesquisa, interessamo-nos pelo ato de imaginar e pelo ato de lembrar e por isso, mais adiante, conceituaremos memória e imaginário. Pretendemos, pelas nossas pesquisas de campo nos seringais, compreender esses atos a partir do método fenomenológico.

Na Geografia, a fenomenologia pura de Edmund Husserl não vem sendo utilizada como única fonte bibliográfica porque muitos se inspiraram em pesquisadores que vieram posteriormente, como Martin Heidegger, Jean-Paul Sartre e Merleau-Ponty.

Martin Heidegger foi um discípulo de Edmund Husserl. Ele se interessava pela questão do ser, temática essa claramente medieval, mas que não instigava tanto a Husserl, pois o último, como vimos, dedicava-se inteiramente à essência e não à existência. Heidegger influenciou-se pela fenomenologia husserliana integrando-a à teoria de São Tomás de Aquino. A sua primeira publicação de "Ser e Tempo" se deu na revista de Husserl, em que o entendimento sobre o tempo era claramente influenciado pelo mestre, mas seus pensamentos afastaram-se e eles romperam relações. Heidegger não deixou de utilizar a fenomenologia, mas passou a ser um dos representantes de outra abordagem conhecida como Existencialismo (ALES BELLO, 2004).

Nicholas Entrikin (1980) afirma que o existencialismo se distancia da fenomenologia de uma forma que não pode ser estabelecida com muita clareza. Os limites são tênues. Eles se interessam pela natureza do ser e trazem, além da influência de Edmund Husserl, uma tradição ética em que o homem é visto como voluntário, ou seja, é por seus objetivos e escolhas que uma situação ocorre. O que está ao redor do homem só tem sentido de acordo com a escolha feita. Eles criticam o determinismo ambiental ao dizer que só depois de uma escolha o ambiente pode ou não facilitar o alcance de algo, mas a escolha é que determinou e não o ambiente. Além do alemão Martin Heidegger, os franceses Merleau-Ponty e Jean-Paul Sartre também contribuíram para o existencialismo.

Angela Bello (2004) explica que Merleau-Ponty abordou o tema da corporeidade que Husserl já trazia, mas dedicando-se à sexualidade. Interessava-se pela percepção, inclusive no âmbito neurológico e refletia sobre temas como a Teoria da Gestalt. Jean-Paul Sartre pesquisou a temática da imaginação negando a existência de Deus, defendendo que se tornava necessário optar pela existência de Deus ou do Eu. Ele trouxe uma das grandes teorizações do ateísmo. Nicholas Entrikin (1980, p. 13) explica que segundo Sartre, um indivíduo que "[...] permite que outros fatores alheios à sua vontade consciente determinem a sua escolha, tal indivíduo está vivendo uma existência inautêntica [...] em má fé", isso corrobora para sua ideia de que Deus não existe pois é um fator alheio.

Ambos, Merleau-Ponty e Jean-Paul Sartre, acreditavam na existência enquanto angústia, ou seja, uma existência dramática que os aproximou do marxismo. O segundo, com suas ideias filosóficas, chegou a ser expulso do partido comunista. Além de Martin Heidegger, Merleau-Ponty e Jean-Paul Sartre, outros pesquisadores continuam a adentrar no âmbito da fenomenologia. Alguns nomes conhecidos são Paul Ricoeur e Emanuel Levinas, que possuem uma raiz religiosa (ALES BELLO, 2004).

A fenomenologia existencial de Martin Heidegger, Merleau-Ponty e Jean-Paul Sartre utiliza-se do método fenomenológico, mas não acredita nas reduções propostas por Edmund Husserl, por considerá- 
las idealistas. Eles desconsideram a possibilidade da transcendência (HOLZER, 2010).Buttimer (1982) acredita que os existencialistas se uniram à fenomenologia buscando adaptar o método fenomenológico para explicar o mundo vivido. Este que os fenomenólogos tradicionais reconheceram a existência, mas não buscaram explicar.

O mundo vivido, de acordo com Buttimer (1982, p. 174), é coletivo, no entanto, cada indivíduo o constrói a sua maneira. Não refletimos sobre ele diariamente porque ele é pré-refletivo e determinante do comportamento. Além disso, atualmente, há grande influência das técnicas sobre o Mundo Vivido. A autora faz questão de diferenciar o Vivido do Representacional, pois o último tem influências positivistas com utilização de categorias científicas, lógicas e matemáticas e "descrever o espaço meramente em termos de sua geometria é uma abordagem inadequada ao entendimento da experiência humana".

Os existencialistas e os fenomenólogos concordam com a existência do Mundo Vivido (Lebenswelt), muito embora os primeiros acreditem que não seja possível transcendê-lo para compreendê-lo, pois vivemos em um mundo. Já Husserl defende que é só por essa transcendência que se encontra a percepção essencial. O Mundo para ambos é construído pelo sujeito pela sua percepção. O mundo é aquilo que aparece à consciência a partir da polaridade existente entre o eu e o outro. No mundo ocorre a nossa história e é nele que encontramos as coisas, os outros e nós mesmos (HOLZER, 2010; ENTRIKIN, 1980).

"Cada pessoa está rodeada por camadas concêntricas de espaço vivido" (BUTTIMER, 1982, p. 178), o que significa que estamos rodeados pelos nossos espaços vividos assim como os espaços vividos estão rodeados de outros. Ainda segundo a autora, o Mundo Vivido está relacionado com as experiências íntimas que compõem o lugar. Mas esse Lugar só pode ser entendido diante da Fenomenologia. Portanto, o lugar, que vinha sendo compreendido de diferentes maneiras, ganha na corrente humanista da Geografia um significado afetivo. Tornase um centro onde se constroem relações emocionais que integram elementos simbólicos, culturais e biológicos, que veremos mais adiante.

$\mathrm{Na}$ Geografia, a espacialização do homem como parte de um mundo vivido é um gancho que a integra à fenomenologia, muito embora com raízes claramente existencialistas. Por isso, para entender o elo do paradigma fenomenológico com a Geografia fizemos esse breve histórico de autores.

Holzer (2010) explica que a fenomenologia vem sendo utilizada na Geografa pelo menos desde a década de 1920, influenciando geógrafos como Carl Sauer, David Lowenthal e Eric Dardel, mas foi apenas nos anos de 1960 que ela se efetivou na ciência geográfica com geógrafos como Anne Buttimer, Yi-Fu Tuan e Relph. Eles compreendem a fenomenologia como "a filosofia dos mundos vividos da experiência humana" (HOLZER, 2010, p. 38), que além de criticar o cientificismo do positivismo, algo que tornava-se fundamental para a Geografia, tem uma visão holística do homem e da natureza através da intencionalidade. Os três utilizaram a Fenomenologia não como um postulado, mas como uma espécie de aporte para as pesquisas, mas Relph eYi-FuTuan se remeteram mais ao humanismo, deixando-a implícita.

O humanismo foi definido porYi-Fu Tuan (1983). O autor explica que o termo teve muitas interpretações ao longo da história, durante muito tempo, e mesmo já no século XX esteve associado a brigas contra a intolerância religiosa. Por vezes direcionou-se ao classicismo como fizeram filósofos da renascença. Todos buscavam de alguma maneira ampliar o entendimento do que é o indivíduo humano e do que ele pode fazer. No entanto, as abordagens científicas têm dado pouca importância ao papel da consciência humana e por isso a Geografia 
Humanística "tenta especificamente entender como as atividades e os fenômenos geográficos revelam a qualidade da conscientização humana" (TUAN, 1983, p. 146). Através dessa compreensão, o humanismo na Geografia acaba por aproximar-se, entre outros, do método fenomenológico, mas como explicou Werther Holzer (2010), a fenomenologia foi utilizada de maneira implícita. Abaixo uma citação de Maria Geralda de Almeida com relação ao humanismo na Geografia:

A corrente humanista busca referências variadas, tem um ecletismo voluntário, sem excluir nenhuma via, pois a exclusão é encarada como um risco de limitação e de empobrecimento. A delimitação espaçotemporal do humanismo recolocou o homem no centro de suas preocupações. (ALMEIDA, 2008, p. 3)

Com o homem colocado no centro, surgem pesquisas como as de Anne Buttimer, que se preocupa em definir a fenomenologia. De acordo com a autora, existem duas noções de fenomenologia: 1) Corposujeito e 2) Intersubjetividade. A primeira pressupõe uma relação direta do homem com o meio, enquanto que a segunda pressupõe um diálogo. Esse diálogo se dá "entre pessoas individuais e a subjetividade do seu mundo" (BUTTIMER, 1982, p. 175). A autora argumenta que o subjetivo e o objetivo não devem ser entendidos como distintos, pelo contrário, um estudo fenomenológico transcende a dualidade cartesiana existente entre ambos. O fato é que a fenomenologia não se identifica com nenhum isoladamente, mas sim com o modo intersubjetivo de análise. Werther Holzer explica que essas duas noções trazidas por Anne Buttimer provêm da união da fenomenologia com o existencialismo que fez surgir.

[...] os temas potencialmente exploráveis pela Geografia: a intencionalidade do homem na estruturação de seu mundo (intencionalidade do corpo-sujeito); e a intersubjetividade,

Geograficidade | v.3, n.1, Verão 2013

ISSN 2238-0205 definida como o diálogo entre o homem e o meio, em termos de herança sociocultural e do papel assumido por ele no mundo vivido. (HOLZER, 2010, p. 40)

Com essa base chegamos agora à Nova Geografia Cultural, assim denominada por ter renascido influenciada pelo paradigma fenomenológico. Utilizaremos uma frase inicial do livro de Joel Bonnemaison (2010, p. 1) "Conceiving a New Cultural Geography": "Cultural Geography positions human beings at the centre of geographical knowledge - human beings with their beliefs, their passions and their life experiences", que se traduz como "Geografia Cultural posiciona o ser humano no centro do conhecimento geográfico - o ser humano com suas crenças, suas paixões, suas vivências". Essa assertiva permite descrever com clareza o que movimenta um geógrafo cultural, além disso, no livro do professor francês encontra-se muito da fenomenologia. É humanismo geográfico, pois se centra no homem, e é extremamente fenomenológico porque se interessa pelas vivências, que nada mais são do que as percepções do homem em relação ao mundo.

Maria Geralda de Almeida (2009) descreve três abordagens da Geografia Cultural que podem ser consideradas mais evidentes:

1) Semiótica - que explora os signos e significados;

2) Espiritualista - que se preocupa com a consciência humana;

3) Eclética - um mosaico de temas/interdisciplinaridade.

A primeira delas se preocupa com o universo de símbolos atribuídos aos espaços e aos lugares, dedicam-se tanto a paisagens urbanas quanto ao meio rural. Denis Cosgrove é um geógrafo que se insere nessa abordagem. A corrente espiritualista é protagonizada pela italiana Giuliana Andreotti e está relacionada aos valores espirituais

2 O termo "life experiences" é uma tradução encontrada na língua inglesa para o vocábulo Eslebnis do alemão. 
que são atribuídos aos lugares. Nessa corrente os geógrafos se interessam pela consciência humana por um viés artístico e poético. A última linha, denominada Eclética, tem como representante principal o francês Paul Claval e possui como característica uma interdisciplinaridade. É um mosaico de diversos temas que possuem procedimentos metodológicos homogêneos.

Independente da abordagem que se siga, esses geógrafos têm buscado compreender o Lugar de maneira diferenciada em relação a estudos anteriores.

\section{HABITAR A TERRA}

O homem habita a Terra. Mas o que é a Terra? Uma simples matéria onde ponho meus pés? E se assim for, como ponho meus pés? Como pisamos sobre cada pedaço de terra da Terra? Nós habitamos - e habitar é muito mais que simplesmente pisar. Habitar é colocar sobre o solo toda a nossa subjetividade (DARDEL, 2011). Nós não vivemos pra pisar, mas para habitar um lugar na Terra.

Nós habitamos o próprio corpo e essa habitação se estende ao mundo que se encontra ao nosso redor. No livro "Paisagens pós-urbanas: o fim da experiência urbana e as formas comunicativas do habitar", Massimo Di Felice (2009) analisa Martin Heidegger para propor três formas comunicativas de habitar que se configuram na atual sociedade tecnológica: 1) Empática, 2) Exotópica e 3) Atópica. A primeira se refere à tecnologia da leitura; a segunda vem da eletricidade e dos meios de comunicação em massa, e a última pelas mídias digitais e virtuais. Sua teoria pode ser muito aplicável ao estudo de sociedades modernas, mas não é facilmente encaixável no estudo de sociedades tradicionais.

Martin Heidegger (2012, p. 100), em seu livro "Ser e Tempo", definiu o conceito Dasein que pode ser traduzido na língua portuguesa como
Ser-aí ou Ser-no-mundo. Esse conceito está relacionado à existência que, por sua vez, provém da presença espacial do ser. O homem tem a sua subjetividade no mundo, sem o qual ela não existiria: "O Ser-em é, pois, a expressão formal e existencial do ser da presença que possui a constituição essencial de ser no mundo". Essa constituição essencial de ser no mundo faz com que ele se espacialize, no entanto, o sujeito não enxerga o mundo como um espaço. O sujeito é um ser espacial pela presença no mundo. $O$ ser no mundo tem um espaço e não existe sem tê-lo, porque existimos "aí".

O espaço nem está no sujeito nem o mundo está no espaço. Ao contrário, o espaço está no mundo à medida que o ser no mundo constitutivo da presença já sempre descobriu um espaço. O espaço não se encontra no sujeito nem o sujeito considera o mundo como se estivesse num espaço. É o sujeito entendido ontologicamente, a presença, que é espacial em sentido originário. Porque a presença é nesse sentido espacial [...] (HEIDEGGER, 2012, p. 166).

A partir dessa definição de Martin Heidegger, entende-se que a presença do sujeito é espacial, ou seja, só pode haver existência em um espaço. Werther Holzer (2010, p. 56) entende que o conceito Dasein seja o gancho fundamental entre a fenomenologia existencial e a Geografia. O ser no mundo pode ser compreendido pela Geografia, pois esta é "[...] o ponto de referência sobre o qual experimentamos a passagem do tempo; ela é a base sem a qual a história não pode acontecer". Portanto, a partir desse conceito, entendemos que o ser habita e por isso - existe. Não há existência sem a presença.

Heidegger (1954, p. 1), em "Construir, habitar, pensar", direcionase ao conceito de habitar sustentado na ideia de existência e faz as seguintes perguntas: 1) O que é habitar? 2) Em que medida pertence ao habitar um construir? Segundo ele, nem todas as construções são 
habitações. É o exemplo das pontes, rodovias, represas, mercados e outros, elas estão no nosso habitar, mas vão além. Um mercado para um mercador é um não habitar e um habitar ao mesmo tempo e, por conseguinte, não se pode afirmar com certeza que a sua casa, e não o mercado, é verdadeiramente o seu habitar. O construir é visto como um meio para o habitar, mas essa relação não garante que haja um fim (habitar) efetivo.

O termo Buan, transformado em Baven é traduzido como construir e seu significado é habitar. O autor defende que é possivel entender três coisas a partir desse termo:

construir (Baven) é propriamente habitar;

habitar (Wohnen) é o modo como os mortais são e estão sobre a terra;

no sentido de habitar, construir desdobra-se em duas acepções: construir, entendido como cultivo daquilo que cresce e o construir no sentido de edificar construções.

Martin Heidegger defende que não habitamos porque construímos, mas sim cada vez mais construímos porque habitamos. Ele discorre sobre o céu, a Terra, os divinos e os mortais como uma unidade complementar. Os mortais habitam a Terra e estar na terra é posicionar-se sob o céu, diante dos divinos. O habitar se compõe por uma quadratura (céu, terra, divinos e mortais), como ele denomina.

Buttimer (1982, p. 166) aprofunda o conceito Dasein relacionando-o diretamente com a natureza. A autora é influenciada pela teoria de Martin Heidegger e entende que habitar é mais que "morar, cultivar ou organizar o espaço. Significa viver de um modo pelo qual se está adaptado aos ritmos da natureza [...] construir um lar que é o símbolo de um diálogo diário com o meio ambiente ecológico e social da pessoa". Portanto, habitar é ter um lar que existe pelo diálogo do natural com o social. A partir do conceito Dasein o homem é colocado como um ser com existência espacial e por isso habita - e essa habitação se chama Terra.

Eric Dardel enxerga a Terra como base onde além de habitar, construímos, cultivamos e circulamos.

A Terra, como base, é advento do sujeito, fundamento de toda consciência a despertar a si mesma; anterior a toda objetivação, ela se mescla a toda tomada de consciência, ela é para o homem aquilo que ele surge no ser, aquilo sobre o qual ele erige todas as duas obras, o solo de seu hábitat, os materiais de sua casa, o objeto de seu penar, aquilo a que ele adapta sua preocupação de construir e erigir. (DARDEL, 2011, p. 41)

Percebemos a partir da definição do autor que o homem e a Terra acabam se confundindo em suas existências. Eles se buscam, encontram-se e se reconhecem. É na Terra que se desenvolve a história do homem e a dela mesma, estando essas histórias interligadas entre si enquanto realidade geográfica. Maria Sirley dos Santos diz:

O planeta Terra sempre foi objeto de curiosidade, fascinação e também de diferentes investigações científicas sobre sua origem, sua forma, seus movimentos, seu tamanho, etc. Terra, morada do homem e de inúmeras espécies de seres pertencentes aos reinos animal e vegetal, cenário onde predomina a diversidade e se aprendem cotidianamente lições de convivência e sobrevivência. (SANTOS, 2009, p. 27)

A convivência é aquilo que nos identifica enquanto sociedade e o homem está inserido em um meio sob determinadas regras sociais de comportamento. Além de conviver, sobrevivemos na Terra criando meios de habitar. Para Tuan (1983, p. 160): "a Terra é o corpo humano em grande escala". Essa afirmação demonstra a relação da existência humana com a Terra visto que a última seria parte da nossa corporeidade. 
Concluímos que Habitar a Terra seja algo inerente a nossa existência. Se existimos: habitamos; se habitamos: habitamos a Terra. Na Terra temos as nossas vivências/atos. As vivências possibilitam que os homens encontrem lugares na Terra. Dardel (2011, p. 43) afirma que a Terra: "assinala a cada existente seu lugar" e podemos complementar dizendo que o homem dá à Terra um lugar dentro de si, do próprio ser. Os lugares são essenciais para a existência na Terra e sempre estamos em busca deles. Ainda de acordo com Eric Dardel (2011, p. 41): "Podemos mudar de lugar, nos desalojarmos, mas ainda é a procura de um lugar".

Martin Heidegger, como vimos, afirma que o ser existe no mundo/ aí/em um lugar, "onde o lugar é determinado pelos laços emocionais do homem, pela inquietação do homem" (ENTRIKIN, 1980, p. 12). Jean-Paul Sartre, como descreve Entrikin (1980, p. 16), dizia que não é possível não ter um lugar, pois "existir é ter um lugar e para o existencialismo o homem nunca pode transcender sua existência ou situação". A Geografia humanista, influenciada pelo existencialismo, retoma as discussões sobre a categoria geográfica Lugar que vinha sendo interpretada de diversas maneiras.

Não há uma unidade de pensamento sobre o que é o Lugar e, por isso, demonstraremos algumas diferenças que vem sendo discutidas.

\section{A GENTE DO LUGAR}

Holzer (1999) faz uma retrospectiva e explica que os geógrafos tradicionais consideravam o lugar como uma importante categoria no estudo geográfico, contudo, com sentido locacional. O período que a ciência atravessou a partir disso, centrando grande parte dos estudos naquilo que consideravam como objetivo e racional, fez com que essa significação locacional não se ampliasse. Carl Saver foi

Geograficidade | v.3, n.1, Verão 2013 ISSN 2238-0205 um dos primeiros a propor alguma transformação quando falou do sentido do lugar, ele trouxe a possibilidade do subjetivo. Lukermann debateu com as ideias do geógrafo americano da escola de Berkeley e definiu a Geografia como a ciência dos lugares, e esse lugar vem das experiências. Mas esse conceito só se fortaleceu verdadeiramente após a década de 1980 .

Tuan (1983) é um dos grandes estudiosos do lugar desse período e da atualidade. Ele discorre a respeito das experiências íntimas com o lugar. Para o autor, o espaço se transforma em lugar quando adquire algum significado. Um lugar pode ser uma área, um objeto ou até mesmo uma pessoa; o importante é que haja um sentido de lar envolvido. Ele compreende que este é resultado das nossas experiências com o mundo, a partir de duas características: identidade e estabilidade. Isso significa que ele é fruto de nossas intenções e experiências em grupo (intersubjetivas), sendo sempre insubstituível. Ele é uma pausa no movimento. Essa pausa, como explica Werther Holzer (1999, p. 73), "[...] não quer dizer, no entanto, que o lugar esteja além da história ou seja atemporal, significa sim, que o lugar denota a relação inseparável entre espaço e tempo".

Mas na atualidade, não apenas os geógrafos humanistas definem o lugar. Ana Fani Carlos (1996) se baseia em Milton Santos para definilo. Segundo a autora, o ser humano possui dimensões diversas que se constituem pelo processo de criação, recriação e superação. Esse processo ocorre fora das fronteiras do lugar visto que atualmente há grande articulação entre o local e o mundial. Criam-se novas atividades, novos comportamentos e novos valores.

[...] a globalização materializa-se concretamente no lugar, aqui se lê/percebe/entende o mundo moderno em suas múltiplas dimensões, numa perspectiva mais ampla, o que significa dizer 
que no lugar se vive, se realiza o cotidiano e é aí que ganha expressão o mundial. (CARLOS, 1996, p. 15)

A autora acredita que o lugar permite entender a produção do espaço atual em todo esse processo de mundialização. O lugar é visto então como uma parcela do espaço, onde se configura a construção social, além disso, este possui a dimensão concreta e real onde se encontra a totalidade e as particularidades, já que cada sociedade produz o espaço de uma determinada maneira. Ana Fani Carlos descreve uma teoria exposta por Milton Santos em um Encontro Nacional em 1995, quando o professor afirmou que o Lugar se constitui por uma densidade técnica, densidade informacional, densidade comunicacional (contato entre as pessoas) e densidade normativa, todas estas envolvidas pela dimensão do tempo. No livro "Da totalidade ao lugar", Santos (2005) explica as três primeiras densidades. A densidade técnica se caracteriza pela tecnologia desenvolvida com grande magnitude em algumas áreas e de maneira quase ínfima em outras; a Informacional varia da anterior, mas centra-se "nos graus de exterioridade do lugar, sua propensão a entrar em relação com outros lugares e a efetivação dessa propensão, privilegiando setores e atores" (SANTOS, 2005, p. 160); a Comunicacional vem da relação entre as pessoas que caracterizam a vida em sociedade.

Milton Santos afirma que hoje os lugares são condição para a existência de relações globais, compara os lugares com as regiões alegando que a distinção entre eles diminui de relevância visto que ambos estão sujeitos às mesmas normas. Ele dá o exemplo das cidades grandes que, além de lugares, são também regiões. $O$ autor define nesse e em outros textos que o espaço geográfico é constituído por sistemas de objetos e sistemas de ações. Os subespaços totalizam o mundo. Esses subespaços seriam os lugares: "Assim, cada lugar se define tanto por sua existência corpórea, quanto por sua existência relacional. É assim que os subespaços existem e se diferenciam uns dos outros (SANTOS, 2005, p.162).

Almeida (2003, p. 73) discorre sobre a teoria exposta acima e define que "os lugares vividos são frutos das relações tecidas entre os homens e o meio e os sentimentos de pertencimento; sentimentos que correspondem às práticas e às aspirações, estando estas relações codificadas por signos que lhes dão sentido".

Verifica-se que essa linha de pensamento (Ana Fani Carlos e Milton Santos) coloca o lugar mais uma vez em um sentido locacional ampliando seu significado apenas quando o considera resultado das dimensões locais e mundiais. Essa compreensão, portanto, não responde aos questionamentos da presente investigação, visto que o lugar, em interpretações fenomenológicas, estende-se ao emocional/ aos sentimentos revelando uma relação mais profunda do que o mero sentido locacional. Iniciamos o artigo entendendo que existimos no mundo pela nossa presença, ou seja, habitamos. As nossas vivências compõem o nosso habitar dando forma a lugares e, como explica YiFu Tuan (1983, p. 160), os lugares são fruto das experiências íntimas, difíceis de serem descritas. Os lugares íntimos são repletos de carinho onde existe conforto e segurança. Há um sentido de lar que caracteriza o lugar: "Este certamente é o significado de lar - um lugar em que cada dia é multiplicado por todos os dias anteriores" (TUAN, 1983, p. 160). Além disso, o lugar sugere permanência que não basta em seu sentido locacional, é preciso ter a sensação, o valor que provém da intimidade. Muitas vezes, "a experiência pessoal cede às opiniões socialmente aceitas" (TUAN, 1983, p. 162) e os lugares acabam se transformando no óbvio coletivo. Por mais difícil que seja expressar as experiências íntimas, elas podem vir à tona. 
René Dubos, em "Namorando a Terra", também se arrisca a definir o que é Lugar partindo do conceito de ambiente. Para ele, o termo ambiente significa algo externo a nós, algo que nos rodeia, exatamente do jeito que vemos a Natureza. "A palavra ambiente não exprime a qualidade das relações que a espécie humana pode, de maneira ideal, estabelecer com a Terra" (DUBOS, 1981, p. 96). Do ambiente queremos além das condições favoráveis para a vida, experiências emocionais e espirituais que "somente podem ser conseguidas mediante uma interação íntima, ou melhor, uma real identificação com os lugares onde vivemos. Essa interação e identificação geram o espírito do lugar". O Lugar seria algo mais complexo que o ambiente, por conter o exterior e o interior de maneira integrada.

Segundo o mesmo autor, o lugar é algo que satisfaz nossos anseios, traz-nos uma sensação de nostalgia, sendo muitos desses lugares construções que foram criadas sem um objetivo biológico ou econômico. Alguns deles são construídos pelo imaginário nacional, outros são atraentes por possuírem montanhas, florestas e parques. "Cada região e cada comunidade tem assim seu próprio espírito de lugar, resultante da prolongada interação das pessoas e de seu ambiente" (DUBOS, 1993, p. 103).

Os Lugares de Memória são definidos por Pierre Nora (1993). Eles se constituem a partir de três características: materiais, simbólicas e funcionais. Material porque são construídos por pessoas; funcional porque possuem conteúdo hipotético que garante a cristalização e transmissão da lembrança (que é a sua função) e simbólico porque devem possuir uma definição que advém de um acontecimento experimentado por poucos, mas adotado pela maioria. Assim, instituições como: museus, parques e bibliotecas seriam lugares de memória. Para Pierre Nora (1993), se a memória ainda existisse não

Geograficidade | v.3, n.1, Verão 2013 ISSN 2238-0205 necessitaríamos de lugares, a memória morreu, o que temos é a história.

Werther Holzer se questiona sobre a aplicabilidade deste conceito à Geografia. Ele critica a utilização do termo lugar de memória porque a definição de Pierre Nora estaria caminhando muito mais para um não lugar, pois o lugar não pode ser destituído de suas características espaciais e transformado em um símbolo.

Proponho que se defina o lugar sempre como um centro de significados e, por extensão, um forte elemento de comunicação, de linguagem, mas que nunca seja reduzido a um símbolo despido de sua essência espacial, sem a qual torna-se outra coisa, para a qual a palavra lugar é, no mínimo, inadequada (HOLZER, 1999, p. 76).

Eric Dardel (2011, p. 34) explica que: "A realidade geográfica é para o homem o lugar onde ele está". Posteriormente, complementa: "Essa relação vivida dos homens com lugares determinados faz verdadeiramente deles, num sentido rigoroso, gente do lugar [...]" (2011, p. 50). Somos, portanto, seres que habitam e que possuem lugares.

\section{É PRECISO CONCLUIR (TEMPORARIAMENTE)...}

A partir das reflexões estabelecidas no presente texto, por meio da fenomenologia e os teóricos que a adotam, podemos compreender sobre a relação existência - essência que construímos enquanto seres que habitam. É importante ressaltar que a teoria de Edmund Husserl, principalmente no que concerne ao método, difere dos existencialistas. Isto porque para Husserl a existência não é fundamental, mas sim óbvia e devemos dedicar-nos a encontrar aquilo que a transcende: a essência. Para Martin Heidegger, como vimos, a existência é a base 
visto que somos porque somos no mundo e habitamos. Na Geografia, o entendimento de Heidegger foi de grande importância para definição de categorias como o lugar. Isso fica claro quando lemos estudos de pesquisadores consagrados na Geografia Cultural Humanista como alguns que citamos ao longo do texto. Todavia, acredito ser possível compreender os lugares e o habitar por uma linha unicamente husserliana, embora eu mesma não tenha, ainda, me arriscado a fazêlo.

Por esse aporte teórico, tornou-se viável buscar a essência do que é viver na floresta amazônica para os ex-seringueiros dos estado do Acre, hoje aposentados como Soldados da Borracha. As vivências nos seringais foram transmitidas por entrevistas narrativas semiestruturadas de modo que discorressem com certa liberdade pela temática. Tanto durante o campo quanto no decorrer da análise do conteúdo, os conceitos de lugar, habitar e mundo vivido têm sido fundamental.

\section{REFERÊNCIAS}

ALES BELLO, Angela. Introdução à fenomenologia. São Paulo: Edusc, 2004 .

ALMEIDA, Maria G. de. (org.) Geografia, leituras culturais. Em busca do poético do sertão: um estudo de representações. Goiânia: Alternativa, 2003.

. Aportes teóricos e os percursos epistemológicos da Geografía Cultural, Revista Geonordeste. São Cristóvão, ano XIX, n. 1, p. 33-54, 2008. Edição Especial.

Geografia Cultural: contemporaneidade e um flashback na sua ascensão ao Brasil. In: MENDONÇA, Francisco de A.; LOWEN-SAHR, Cicilian L.; SILVA, Márcia da. (orgs.) Espaço e tempo: complexidade e desafios do pensar e do fazer geográfico. Curitiba: Ademadan, 2009. 740p.

BELLO, Angela Agnes. Introdução à fenomenologia. São Paulo: Edusc, 2004.

BUTTIMER, Anne. Aprendendo o dinamismo do mundo vivido. In: CHRISTOFOLETTI, Antonio. (org.) Perspectivas da geografia. São Paulo: Difel, 1982.

CARLOS, Ana Fani Alessandri. O lugar no/do mundo. São Paulo: Hucitec, 1996.

DARDEL, Eric. O Homem e a Terra: natureza da realidade geográfica. São Paulo: Perspectiva, 2011.

DI FELICE, Massimo. Paisagens pós-urbanas: o fim da experiência urbana e as formas comunicativas do habitar. São Paulo: Annablume, 2009.

DUBOS, René. Namorando a Terra. São Paulo: Melhoramentos, 1981. 150p.

ENTRIKIN, Nicholas. O Humanismo Contemporâneo em Geografia, Boletim de Geografia Teorética, Rio Claro, v. 10, n. 19, p. 5-30, 1980.

HEIDEGGER, Martin. Construir, habitar, pensar. In: Ensaios e conferências. Tradução: Emamanuel C. Leão. Petrópolis: Vozes, 2001.

Ser e Tempo. Petrópolis: Vozes, 2012. 598p.

HOLZER, Werther. Paisagem, imaginário, identidade: alternativas para o estudo geográfico. In: ROSENDAHL, Zeny; CORRÊA, Roberto L. (orgs.) Manifestações da cultura no espaço. Rio de Janeiro: Eduerj, 1999.

O método fenomenológico: humanismo e a construção de uma nova Geografia. In: ROSENDAHL, Zeny; CORREAA, Roberto L. (orgs.) Temas e caminhos da Geografia Cultural. Rio de Janeiro: Edverj, 2010.

HUSSERL, Edmund. Ideias para uma fenomenologia pura e para uma filosofia fenomenológica. $2^{\text {a }}$ ed. São Paulo: Ideias \& Letras, 2006. 
Habitar a terra e a gente do lugar - uma abordagem fenomenológica para compreensão da memória de seringueiros do estado do Acre

NORA, Pierre. Entre história e memória: a problemática dos lugares, Revista Projeto História. São Paulo, v. 10, p. 7-28, 1993.

PORTO-GONÇALVES, Carlos Walter. Os (des)caminhos do meio ambiente. $8^{\mathrm{a}}$ ed. São Paulo: Contexto, 2001.
SANTOS, Milton. Da totalidade ao lugar. São Paulo: Edusp, 2005. $170 \mathrm{p}$.

TUAN, Yi-Fu. Espaço e Lugar: a perspectiva da experiência. São Paulo: Difel, 1983. 250p. 